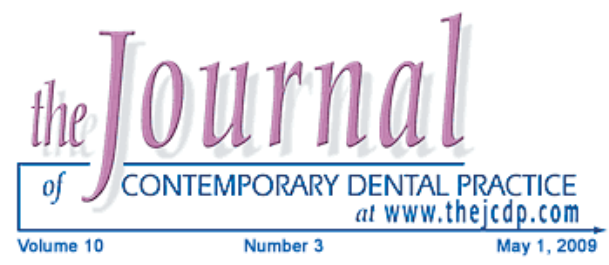

\title{
Inadequate Vertical Bone Dimension Managed by Bone-added Osteotome Sinus Floor Elevation (BAOSFE): A Literature Review and Case Report
}

\section{Shilpa Kolhatkar, DDS, MDS; Leyvee Cabanilla, DDS, MSD;}

Monish Bhola, DDS, MSD

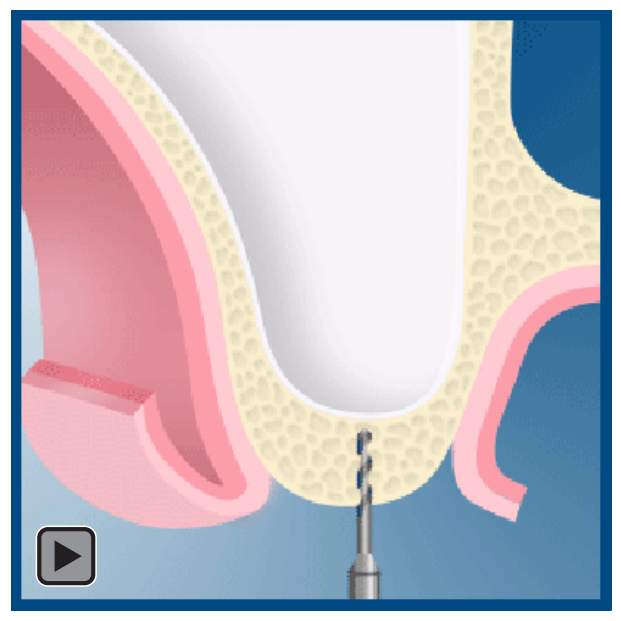

Abstract

Aim: The purpose of this report is to provide a brief literature review of the bone-added osteotome sinus floor elevation (BAOSFE) procedure and to present a case utilizing this technique.

Background: Implant placement in the posterior maxillary region is often compromised due to anatomic limitations. In clinical situations where there is inadequate vertical bone dimension, the BAOSFE technique can be employed to increase bone height and allow placement of implants with an appropriate length dimension.

Case Report: A case of a 60-year-old female with inadequate vertical bone dimension in the area of an extracted \#13 is presented. The BAOSFE technique was performed which facilitated the placement of a $3.75 \mathrm{X}$ $13 \mathrm{~mm}$ implant.

Summary: Anatomic limitations such as inadequate vertical bone dimension in the posterior maxillary region may result in placement of shorter implants. Sinus floor elevation (SFE) procedures using a crestal approach such as the BAOSFE, in certain selected cases, can effectively and predictably increase bone height.

Clinical Significance: The BAOSFE technique is an excellent procedure that can overcome limitations associated with the posterior maxillary region.

(c) Seer Publishing 
Keywords: Dental implants, bone-added osteotome sinus floor elevation, BAOSFE, sinus lift, osteotome technique, bone grafts, sinus floor elevation, SFE

Citation: Kolhatkar S, Cabanilla L, Bhola M. Inadequate Vertical Bone Dimension Managed by Bone-added Osteotome Sinus Floor Elevation (BAOSFE): A Literature Review and Case Report. J Contemp Dent Pract 2009 May; (10)3:081-088.

\section{Introduction}

The use of implants has significantly increased prosthetic options for the edentulous patient. However, implant placement in the posterior maxillary region is often hampered significantly by anatomic limitations like inadequate vertical dimension, poor bone quality, ${ }^{1-5}$ thinning or missing cortex ${ }^{6}$ and undercuts. ${ }^{7}$

For implant placement in the posterior maxillary region, the maxillary sinus is one of the most important anatomic structures. Following tooth extraction, the periosteum of the maxillary sinus can exhibit an increase in osteoclastic activity. ${ }^{8}$ The resulting reduced bone height due to pneumatization of the maxillary sinus influences the length and location of implants. Previously, many fixed restorations terminated at the second premolar due to insufficient alveolar ridge height. ${ }^{9}$ Many reports have also concluded when shorter implants $(<10 \mathrm{~mm})$ are placed, they are less successful than longer implants., ${ }^{40-13}$ Thus, procedures like sinus floor elevation (SFE), which facilitate placement of longer implants in the posterior maxilla, have received a lot of attention in recent years.

\section{Literature Review}

SFE has been referred to as maxillary sinus elevation, maxillary sinus lift, sinus grafting, and subantral augmentation. The first report on the SFE technique using the lateral approach was published in 1980 by Boyne and James ${ }^{14}$ although Tatum had presented this concept in $1977 .^{15,16}$ This bone augmentation procedure has been modified many times, but its long-term success has been well documented. ${ }^{17,18}$ One such modification was presented by Summers in 1994. ${ }^{19}$ This technique uses a crestal approach and recommends the use of specific root analog instruments (osteotomes).
The Summers osteotome sinus floor elevation (OSFE) technique is more conservative than the more traditional lateral approach to the sinus. It offers the advantages of reduced morbidity, ${ }^{20}$ shorter surgical time, ${ }^{21}$ and reduced postoperative discomfort. ${ }^{22}$ The aim of the procedure is to retain all the available bone and compact it laterally or superiorly. The antral floor is abfractured using root analog instruments with concave tips. The addition of a bone graft into the osteotomy is referred to as the bone-added osteotome sinus floor elevation (BAOSFE) created with the concave tips of the osteotome which provide bone shavings that, along with trapped fluid, help elevate the sinus floor upward. This bone graft is thought to provide a cushion during membrane elevation and reduces the risk for membrane perforation.

A thorough pre-operative assessment including clinical evaluation and a radiographic examination are essential to evaluate the amount of bone present. The radiographic examination should include conventional radiography (periapical and panoramic films) and sometimes more advanced imaging techniques like cone beam computer tomography (CBCT). Although Summers ${ }^{19}$ did not define a minimum presurgical residual bone height $(\mathrm{RBH})$ in the original article, other authors have made recommendations ranging from $8-10^{23}$ to $6 \mathrm{~mm}^{22} \mathrm{~A}$ multicenter study by Rosen and colleagues $^{24}$ found a minimum $\mathrm{RBH}$ of $4 \mathrm{~mm}$ was necessary for a high rate of success for implants placed using the BAOSFE technique.

The consensus conference on sinus lifting held in $1996^{23}$ made several recommendations for the surgical protocol for implant placement based on the volume of $\mathrm{RBH}$. They divided the $\mathrm{RBH}$ into four categories:

1. Class $A,>10 \mathrm{~mm}$, for which the classic implant protocol could be followed. 
2. Class B, 7-9 mm for which a BAOSFE could be performed along with simultaneous implant placement.

3. Class $\mathrm{C}, 4-6 \mathrm{~mm}$ would require a lateral approach with delayed or immediate implant placement.

4. Class $D$, when there is only $1-3 \mathrm{~mm}$ of bone, a lateral approach with delayed implant placement is recommended.

In 2003, Fugazzatto ${ }^{25}$ recommended using the final implant length as a guide for BAOSFE. If the remaining bone height is equal to at least half the final implant length and if there is adequate buccolingual bone width, he recommended simultaneous BAOSFE and implant placement.

Reports describing the amount of elevation that can be predictably achieved have also varied significantly. In 2001, Reiser and colleagues ${ }^{26}$ used a $2 \mathrm{~mm}$ twist drill to prepare the implant site to within $1 \mathrm{~mm}$ of the sinus floor in human cadavers. They found the sinus floor could be predictably elevated by $4-5 \mathrm{~mm}$ and often up to 6-8 mm. Nkenke and co-workers ${ }^{27}$ performed an OSFE using endoscopy. They recommended 3 $\mathrm{mm}$ elevation for procedures done without the benefit of endoscopic visualization for membrane perforations. Findings published by Fugazzotto ${ }^{25}$ reported wide range of bone gain $(1-7 \mathrm{~mm})$ with a mean bone gain being $3.5 \mathrm{~mm}$.

The following is a step-by-step description of the BAOSFE technique:

1. Accurately predetermine available bone.

2. Make a crestal incision towards the palatal aspect of the anticipated osteotomy site and raise a full thickness flap for adequate visualization.

3. Use a small round bur to mark the implant site.

4. Use a $2 \mathrm{~mm}$ twist drill to the depth of $1 \mathrm{~mm}$ short of the sinus floor (Figure 1).

5. Verify the depth with a radiograph.

6. Widen the osteotomy site to $3 \mathrm{~mm}$ with a twist drill.

7. Verify the depth with a radiograph.

8. Place the bone graft of choice into the osteotomy site using a sterile amalgam carrier.

9. Use a suitably sized osteotome $(<3 \mathrm{~mm})$, advance by $1 \mathrm{~mm}$ with each mallet stroke till the sinus floor is infractured (Figure 2).

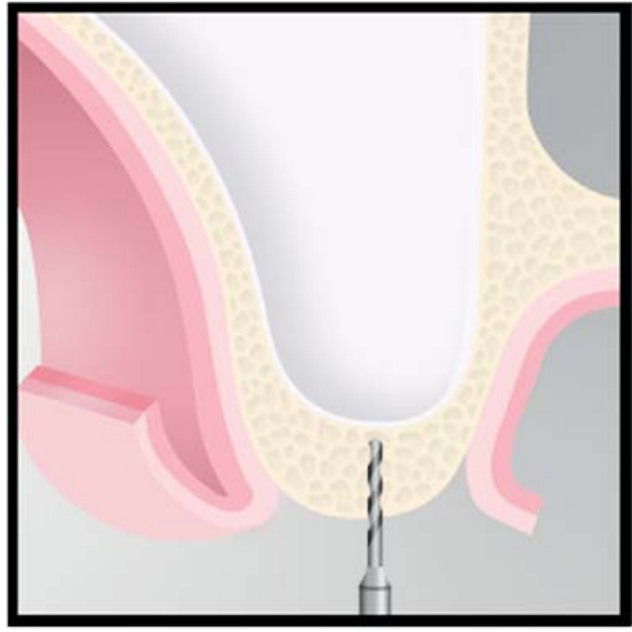

Figure 1. Drill to depth of $1 \mathrm{~mm}$ short of the sinus floor.

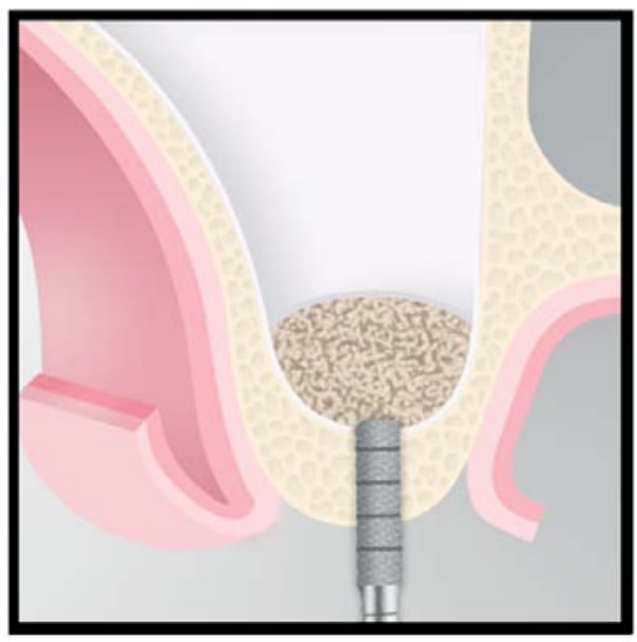

Figure 2. Osteotome with bone graft to the elevate sinus floor.

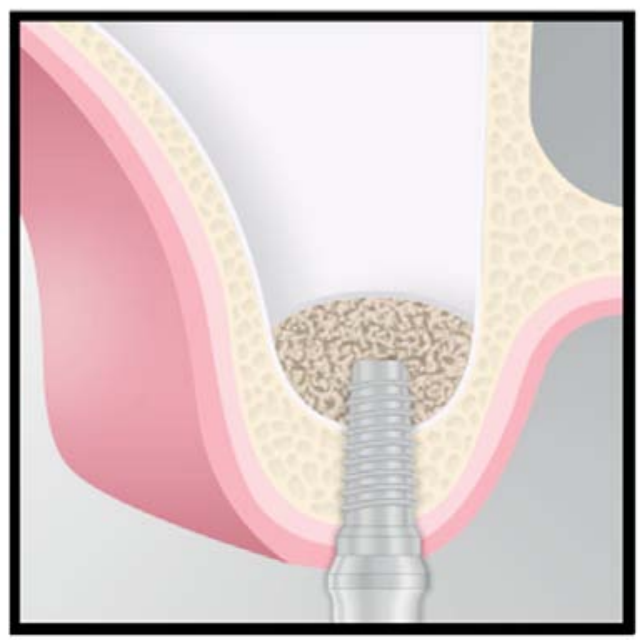

Figure 3. Implant with sinus floor elevation. 
10. Check the membrane integrity by having the patient perform a Valsalva maneuver.

11. Place an additional load (about $3 \mathrm{~mm}$ ) of bone graft in the osteotomy.

12. Advance the osteotome into the osteotomy to only the preoperative depth $(1 \mathrm{~mm}$ short of the sinus floor). The sinus floor is elevated primarily by the bone graft.

13. Continue to place bone graft and advance the osteotome using the mallet until the desired bone height is attained. The estimation of the amount of elevation achieved can be based on $1 \mathrm{~mm}$ elevation for each amalgam carrier load of bone graft.

14. Widen the osteotomy to the final diameter using larger osteotomes.

15. Place the final carrier load of bone graft prior to implant placement. The implant performs the final step in sinus elevation ${ }^{26}$ (Figure 3).

16. Suture the flap to ensure tension free closure.

A variety of materials have been used in the BAOSFE technique. Coatoam and $\mathrm{Krieger}^{21}$ used demineralized freeze-dried bone allograft and autogenous bone while Deporter and colleagues ${ }^{28}$ used anorganic bovine bone mineral. Others have used autogenous bone and collagen sponge, ${ }^{29}$ deproteinized bovine bone granules (DBBG), demineralized freeze-dried bone powder (DFBP), and porous hydroxyapatite $(\mathrm{PHA}){ }^{30}$

BAOSFE can also be performed in single or multiple sites. If multiple implants are to be placed, elevation is begun on the anterior implant and the subsequent posterior elevation of the membrane is easier to perform.

The BAOSFE technique can also be complicated by intra and post operative complications.

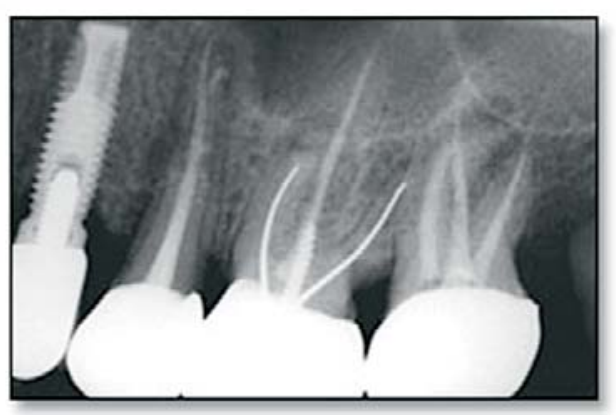

Figure 4. Periapical radiograph of \#13 demonstrating widened PDL.
Membrane perforation is one such complication. If the perforation is small and the bone graft is not dispersed into the sinus, then it is not likely to have an adverse effect on the healing of implants. ${ }^{31}$

\section{Case Report}

A 60-year-old Caucasian female presented with a complaint of pain and tenderness in the maxillary left quadrant of her dentition. Tooth \#13 (maxillary left second pre-molar) showed a widened PDL space (Figure 4).

An endodontic consult recommended retreatment of the existing root canal filling. Endodontic retreatment was performed which involved removal of the silver cone and obturation with gutta percha. At the obturation appointment, a radiolucent line indicative of an accessory canal or fracture was observed. One month after endodontic retreatment, the patient returned to the clinic complaining of pain and swelling which was resolved by antibiotics (amoxicillin $500 \mathrm{mg}$ tid $X 7$ days). Exploratory surgery was recommended to investigate the possibility of a vertical root fracture in tooth \#13. The surgery revealed the presence of a vertical fracture on the facial aspect of the tooth so it was extracted atraumatically (Figure 5).

The patient was given different treatment options and agreed to have an implant placed in the new edentulous space. A socket preservation procedure was not performed. The patient returned to the clinic for implant placement with osteotome sinus lift eight months after the extraction. The dimensions of available bone was $9 \mathrm{~mm}$ buccolingually and $9 \mathrm{~mm}$ apicocoronally (Figure 6).

An osteotomy was performed using a $2.8 \mathrm{~mm}$ twist drill to a depth of $8 \mathrm{~mm}$ (Figure 7). A bone graft

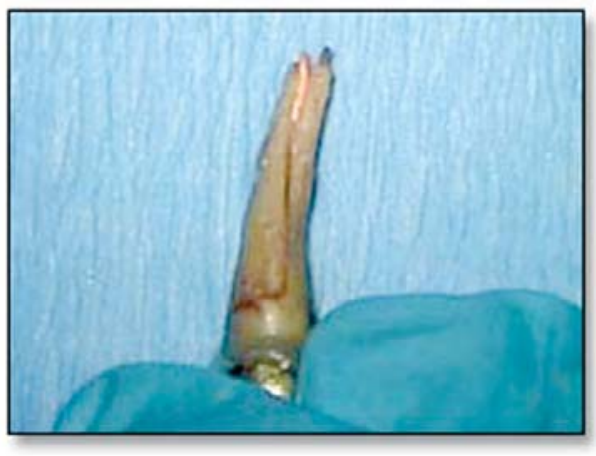

Figure 5. Extracted \#13 showing vertical root fracture. 
was inserted ( $0.25 \mathrm{cc}$ BIO OSS) and osteotomes were used to abfracture the sinus floor. Then a $3.75 \times 13 \mathrm{~mm}$ implant (Nobel Biocare) was placed (Figure 8). A prescription was given to the patient for Keflex 500 mg (14 tabs, 1 tab q 12 h X 7 days).

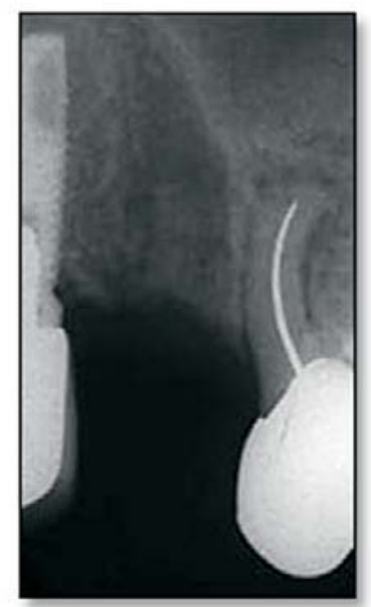

Figure 6. Radiograph eight months after extraction of \#13.

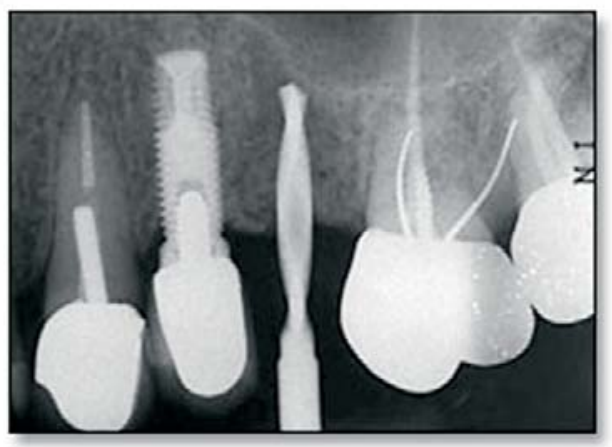

Figure 7. Osteotomy site prepared to a depth of $8 \mathrm{~mm}(1 \mathrm{~mm}$ short of the sinus floor).

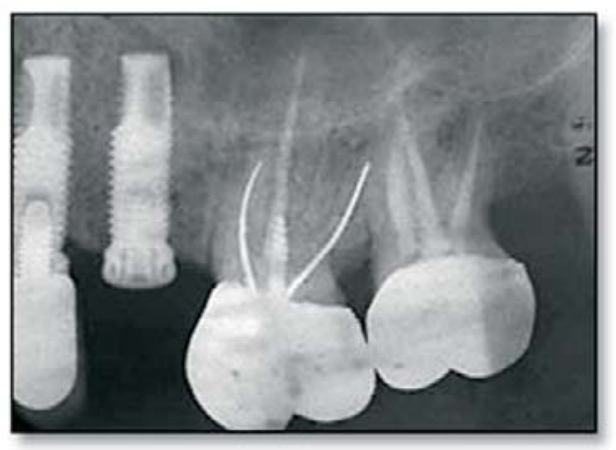

Figure 8. Periapical radiograph with elevated sinus floor and a $3.75 \times 13 \mathrm{~mm}$ implant.
Post operative healing was uneventful, and the implant was restored six months after placement. The patient was seen for a one year follow up. A periapical radiograph taken at that time revealed good bone support and increased density of the sinus floor (Figure 9).

\section{Discussion}

BAOFE procedures were introduced in 1994 by Summers and have undergone several modifications. Survival of implants placed using the BAOSFE technique compare favorably with those placed in non-grafted sinuses. A meta-analysis conducted by Tong and coworkers ${ }^{17}$ reported on implant survival after functional loading for 18 months or more. The survival rate was $90 \%$ when autogenous bone alone was used and $94 \%$ when a combination of hydroxyapatite and autogenous bone was used. The survival rate increased to $98 \%$ when a combination of demineralized freezedried bone and hydroxyapatite was used. When hydroxyapatite alone was used, the survival rate was $87 \%$. Based on this data, the authors suggested implant survival rates were similar for the different grafting materials.

The favorable survival rate of implants inserted using osteotomes can be attributed to the change in density of the alveolar bone. The compressive action of the osteotomes on the lateral walls of the osteotomy may lead to greater primary implant stability and perhaps greater implant-to-bone contact area.

\section{Summary}

Anatomic limitations such as inadequate vertical bone dimension in the posterior maxillary region

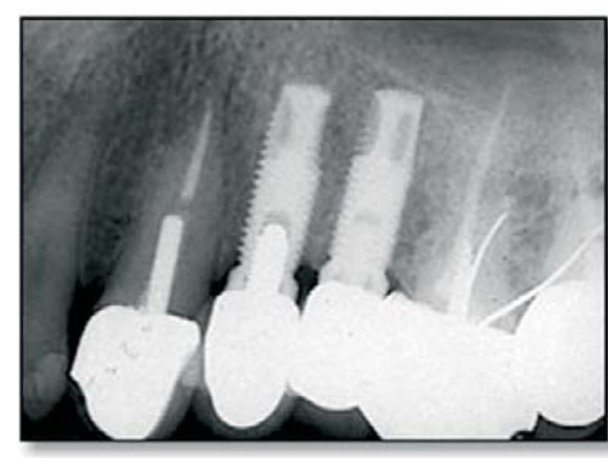

Figure 9. Periapical radiograph one year post restoration placement. 
may result in placement of implants that are shorter than ideal length. SFE procedures using a crestal approach such as the BAOSFE, in certain selected cases, can effectively and predictably increase bone height. This technique, which abfracts and elevates the antral floor using root analog instruments or osteotomes, is more conservative than the conventional lateral approach to the sinus. The addition of bone grafts into the osteotomy is thought to provide cushion during elevation which reduces the risk for membrane exposure. The BAOSFE with simultaneous implant placement can be performed if the residual bone height is at least half the final implant length. A mean bone gain of $3.5 \mathrm{~mm}^{25}$ through osteotome sinus elevation can be achieved. Implants placed in these grafted sites with favorable success rates has been demonstrated. ${ }^{17}$

\section{Clinical Significance}

The BAOSFE technique is an excellent procedure that can overcome limitations associated with the posterior maxillary region. 


\section{References}

1. Bryant SR. The effects of age, jaw site, and bone condition on oral implant outcomes. Int J Prosthodont 1998; 11:470-490.

2. Truhlar RS, Orenstein IH, Morris HF, Ochi S. Distribution of bone quality in patients receiving endosseous dental implants. J Oral Maxillofac Surg 1997; 55:38-45.

3. Esposito M, Hirsh JM, Lekholm U, Thomsen P. Biological factors contributing to failures of osseointegrated oral implants. (II). Etiopathogenesis. Eur J Oral Sci 1998; 106:721-764.

4. Sennerby L, Roos J. Surgical determinants of clinical success of osseointegrated oral implants: a review of the literature. Int J Prosthodont 1998 Sept;11:408-420.

5. Adell R, Lekholm U, Rockler B, Branemark PI. A 15-year study of osseointegrated implants in the treatment of the edentulous jaw. Int J Oral Surg 1981; 10:387-416.

6. Jaffin RA, Berman CL. The excessive loss of Branemark fixtures in type IV bone: a 5-year analysis. Periodontol 1991; 62:2-4.

7. Bahat O. Treatment planning and placement of implants in the posterior maxillae: report of 732 consecutive Nobelpharma implants. Int J Oral Maxillofac Implants 1993; 8:151-161.

8. Misch C. Contemporary Implant Dentistry. St. Louis, Mo: Mosby;1993: 469-485.

9. Pietrokovski J. The bony residual ridge in man. J Prosthet Dent 1975; 34:456-462.

10. Beschnidt SM, Muche R, Krausse A, Strub JR. Implant survival and success rates in partially edentulous patients-Part I ( in German). Schweiz Monatsschr Zahnmed 2003; 113:396-403.

11. Buser D, Mericske-Stern R, Bernard JP, Behneke A, Behneke N, Hirt HP, Belser UC, Lang NP. Long-term evaluation of non-submerged ITI implants. Part 1: 8-year life table analysis of a prospective multi-center study with 2359 implants. Clin Oral Implants Res 1997; 8:161-172.

12. Guttenberg SA. Longitudinal report on hydroxyapatite-coated implants and advanced surgical techniques in a private practice. Compend Suppl 1993; S549-S553.

13. Jemt T, Lekholm U. Implant treatment in edentulous maxillae: a 5-year follow-up report on patients with different degrees of jaw resorption. Int J Oral Maxillofac Implants. 1995; 10:303-311.

14. Boyne PJ, James RA. Grafting of the maxillary sinus floor with autogenous marrow and bone. J Oral Surg. 1980; 38:613-616.

15. Tatum OH Jr. Lectures presented at the Alabama implant Study Group,1977; cited in Smiler DG, Johnson PW, Lozada JL, Misch C, Rosenlicht JL, Tatum OH Jr, Wagner JR. Sinus lift grafts and endosseous implants. Treatment of the atrophic posterior maxilla. Dent Clin North Am 1992; 36:151-186.

16. Tatum H Jr. Maxillary and sinus implant reconstructions. Dent Clin North Am 1986; 30:207-229.

17. Tong DC, Rioux K, Dragsholt M, Beirne OR. A review of survival rates for implants placed in grafted maxillary sinuses using meta-analysis. Int J Oral Maxillofac Implants. 1998; 13:175-182.

18. Jensen OT, Shulman LB, Block MS, lacono VJ. Report of the Sinus Consensus Conference of 1996. Int J Oral Maxillofac Implants. 1998; 13(Suppl):11-45.

19. Summers RB. A new concept in maxillary implant surgery: the osteotome technique. Compendium 1994; 15:152,154-156, 158.

20. Davarpanah M, Martinez H, Tecucianu JF, Hage G, Lazzara R. The modified osteotome technique. Int J Periodontics Restorative Dent 2001; 21:599-607.

21. Coatoam GW, Kreiger JT. A four-year study examining the results of indirect sinus augmentation procedures. J Oral Implantol 1997; 23:117-127.

22. Zitzmann NU, Schaerer P. Sinus elevation procedures in the resorbed posterior maxilla. Comparison of the crestal and lateral approaches. Oral Surg Oral Med Oral Pathol Oral Radiol Endod 1998; 85:8-17.

23. Jensen OT, Shulman LB, Block MS, lacono VJ. Report of the Sinus Consensus Conference of 1996. Int J Oral Maxillofac Implants 1998; 13 Suppl:11-45.

24. Rosen PS, Summers R, Mellado JR, Salkin LM, Shanaman RH, Marks MH, Fugazzotto PA. The bone-added osteotome sinus floor elevation technique: multicenter retrospective report of consecutively treated patients. Int J Oral Maxillofac Implants 1999; 14:853-858. 
25. Fugazzatto PA. Augmentation of the posterior maxilla: a proposed hierarchy of treatment selection. J Periodontol 2003; 74:1682-91.

26. Reiser GM, Rabinovitz Z, Bruno J, Damoulis PD, Griffin TJ. Evaluation of maxillary sinus membrane response following elevation with the crestal osteotome technique in human cadavers. Int $\mathrm{J}$ Oral Maxillofac Implants 2001; 16:833-840.

27. Nkenke E, Schlegel A, Schultze-Mosgau S, Neukam FW, Wiltfang J. The endoscopically controlled osteotome sinus floor elevation: a preliminary prospective study. Int J Oral Maxillofac Implants 2002; 17:557-566.

28. Deporter D, Todescan R, Caudry S. Simplifying management of the posterior maxilla using short, porous-surfaced dental implants and simultaneous indirect sinus elevation. Int J Periodontics Restorative Den. 2000; 20:476-85.

29. Cavicchia F, Bravi F, Petrelli G. Localized augmentation of the maxillary sinus floor through a coronal approach for the placement of implants. Int J Oral Maxillofac Implants 2001; 21:475-485.

30. Karabuda C, Ozdemir O, Tosun T, Anil A, Olgaç V. Histological and clinical evaluation of 3 different grafting materials for sinus lifting procedure based on 8 cases. J Periodontol 2001; 72:1436-42.

31. Berengo M, Sivolella S, Majzoub Z, Cordioli G. Endoscopic evaluation of the bone-added osteotome sinus floor elevation procedure. Int J Oral Maxillofac Surg 2004; 33:189-194.

\section{About the Authors}

\section{Shilpa Kolhatkar, DDS, MDS}

Dr. Kolhatkar is a Clinical Assistant Professor in the Department of Periodontology and Hygiene at the University of Detroit Mercy School of Dentistry in Detroit, MI, USA. She also maintains a private practice limited to periodontics and implant dentistry in Troy, MI, USA. Her research interests include clinical aspects of periodontics especially esthetic and plastic periodontal procedures. Dr. Kolhatkar's professional memberships include the American Academy of Periodontology, Midwest Society of Periodontology, Michigan Periodontal Association, and the American Dental Education Association. She is also a Diplomate of the American Board of Periodontology.

e-mail: kolhatsh@udmercy.edu

\section{Leyvee Cabanilla, DDS, MSD}

Dr. Cabanilla is an Assistant Professor in the Department of Periodondology and Hygiene at the University of Detroit Mercy School of Dentistry in Detroit, MI, USA. She also maintains a private practice limited to periodontics and implant dentistry in Lincoln Park, Westland, and Commerce Township, MI, USA. Her research interests include clinical aspects of periodontics. Dr. Cabanilla's professional memberships include the American Academy of Periodontology, American Dental Association, Michigan Dental Association, Midwest Society of Periodontology, Michigan Periodontal Association, American Dental Education Association, and the Russell Bunting Periodontal Society. She is also a Diplomate of the American Board of Periodontology.

e-mail: cabanill@udmercy.edu

Monish Bhola, DDS, MSD

Dr. Bhola is an Associate Professor in the Department of Periodontology and Hygiene at the University of Detroit Mercy School of Dentistry in Detroit, MI, USA. Dr. Bhola also serves as the Director of PostGraduate Periodontics and the Co-Director of Implant Dentistry. He also maintains a private practice limited to periodontics and implants in Waterford, MI, USA. He is currently a reviewer for the Journal of Periodontology, a member of the research committee of the American Academy of Periodontology, an ambassador for the American Academy of Periodontology Foundation, and serves on the board of 
directors for the Mid-West Society of Periodontology. His research interests include clinical aspects of periodontics. Dr. Bhola's professional memberships include the American Academy of Periodontology, American Dental Association, Michigan Dental Association, Midwest Society of Periodontology, Michigan Periodontal Association, and the Russell Bunting Periodontal Society. He is also a Diplomate of the American Board of Periodontology.

e-mail: bholamo@udmercy.edu 